VIEWING TEAM SELECTION THROUGH A TEMPORAL LENS

\author{
Jonathan Pinto \\ Imperial College Business School \\ Tanaka Building \\ South Kensington \\ London SW7 2AZ \\ Tel: 0207-594-8543 \\ Email: j.pinto@imperial.ac.uk
}

January 2017 


\title{
VIEWING TEAM SELECTION THROUGH A TEMPORAL LENS
}

\begin{abstract}
This paper builds synthesized coherence (Locke \& Golden-Biddle, 1997) across disciplines such as organizational behavior, personnel psychology, entrepreneurship, project management, and strategic management by developing a temporal team selection framework that delineates three temporal team selection processes (i.e., simultaneous selection, sequential selection, and substitution selection). Of these three processes, sequential selection, which could either be constraint-driven or coevolution-driven, is a new conceptualization. This framework speaks to the broader research stream on membership dynamics, and therefore its key constructs such as arithmetic of membership change (Arrow \& McGrath, 1993) and temporal patterning of membership change (Arrow \& McGrath, 1993), have been systematically applied to the temporal team selection processes. Finally, the implications of this theorizing for both research and practice are discussed.
\end{abstract}


Teams scholars generally agree that selecting the right team members is a key determinant of team effectiveness (Mohammed, Cannon-Bowers, \& Foo, 2010), and accordingly team composition as an antecedent to team outcomes has been investigated extensively. But the antecedents to team composition in general, and team selection processes in particular, have been, until recently, relatively neglected. Scholars across a range of disciplines have called for more research into the drivers of team composition. These disciplines include organizational behavior (OB) (Mohammed, Mathieu, \& Bartlett, 2002; Vinkenburg, Jansen, Dries, \& Pepermans, 2014), social psychology (Moreland \& Levine, 2003), industrial-organizational (IO) psychology (Morgeson, Reider, \& Campion, 2005), human resource management (HRM) (Munyon, Summers, \& Ferris, 2011), strategy (Conger \& Lawler, 2001), entrepreneurship (Forbes, Borchert, Zellmer-Bruhn, \& Sapienza, 2006), education (Connerley \& Mael, 2001), and innovation (Henneke \& Luthje, 2007).

This paper not only responds to these calls but also, firstly, provides a synthesized coherence (Locke \& Golden-Biddle, 1997) across these disciplines by developing a temporal team selection framework. Secondly, as the name suggests, the framework is fundamentally temporal and therefore addresses the issue that the role of time has been relatively neglected both in teams research in general, and in team selection scholarship in particular. Thirdly, the framework applies key constructs from the theory of membership dynamics (Arrow \& McGrath, 1993; Summers, Humphrey, \& Ferris, 2012) to provide a nuanced and fine-grained perspective on team selection and its potential impact on team performance. Finally, this framework introduces a new temporal conceptualization, i.e., sequential selection. I elaborate on each of these four contributions in the following paragraphs.

Firstly, this framework provides a synthesized coherence (Locke \& Golden-Biddle, 1997) across several disciplines and research domains. According to Locke and GoldenBiddle (1997, p. 1030) a manuscript displays synthesized coherence when it cites and draws 
"connections between works and investigative streams not typically cited together to suggest the existence of undeveloped research areas." Thus, although team selection is an important topic of research in the afore-mentioned disciplines there has been relatively little crosspollination of ideas or citing of research evidence across them. This may be partly because there is a lack of common unifying framework and terminology across these disciplines. And this is exactly what this paper provides, by developing a parsimonious integrative framework which uses terminology that is simple and unifying by not being discipline-specific. The framework encompasses three selection processes, each of which has been typically studied in particular disciplines, albeit not under these names, i.e., simultaneous selection (e.g., OB and IO psychology inter alia), sequential selection (e.g., entrepreneurship, project management) and substitution selection (e.g., strategic management).

Secondly, this framework is fundamentally temporal and chronological in which time is "a nonspatial continuum in which events occur in apparently irreversible succession from the past through the present to the future" (Ancona, Okhuysen, \& Perlow, 2001, p. 513). In simultaneous selection all decisions are made in the present, in close temporal proximity to one another whereas in sequential and substitution selection most of the selection decisions are made in the future and the past respectively. In terms of the two major conceptual temporal dichotomies delineated by Crossan, Cunha, Vera, and Cunha (2005), i.e., clock versus event time, and linear versus cyclical time, this paper focuses on event and linear time. Thus this paper responds to calls for more focus on time in research in general, and with regard to teams in particular (e.g., Ancona et al., 2001; George \& Jones, 2000; Ilgen, Hollenbeck, Johnson, \& Jundt, 2005; Roe, Gockel, \& Meyer, 2012; Sonnentag, 2012).

This paper is, to the best of my knowledge, the first one to apply an explicitly temporal framing to team selection. Even papers that are entirely focused on the temporal aspects of groups and teams, with subtitles such as The temporal perspective on groups (Arrow, Poole, 
Henry, Wheelan, \& Moreland, 2004) and Considering time at multiple stages of group research (Ballard, Tschan, \& Waller, 2008) completely ignore the role of time at the team formation or selection stage. This is because these papers and the bulk of the groups and teams research implicitly assume that interactions, processes, and dynamics occur only after formation or selection and therefore time is relevant only then (e.g., Bradley, White, \& Mennecke, 2003; Marks, Mathieu, \& Zaccaro, 2001). Thus, they are also implicitly assuming that all teams are formed through simultaneous selection. But as this paper explicates, that is only one team selection process, and in the other two, i.e., sequential selection, and substitution selection, both time and temporal constructs (such as intervals, timing, sequence, and evolution) are relevant and should be studied accordingly.

Thirdly, this framework also speaks to the broader research stream on membership dynamics (Arrow \& McGrath, 1993, 1995; Summers, Humphrey, \& Ferris, 2012). Whereas Arrow and McGrath's (1993) theory of membership dynamics encompasses patterns of continuity and change in team composition including "the arrival of new members, temporary absences, permanent departures, turnover and replacement, or the occasional participation of irregular members, such as guests" (Arrow \& McGrath, 1993, p. 334), this paper focuses only on the selection of new team members. It nevertheless maps onto Arrow and McGrath's (1993) arithmetic of change model. Arrow and McGrath (1993) distinguish between addition, i.e., arrival of a new member, subtraction, i.e., departure of an old-timer, and replacement, i.e., substitution of one member for another. The temporal team selection framework addresses all three in the following manner. Sequential selection involves selecting a new member who would be added to the existing team members. Substitution selection is trigged by a subtraction, i.e., the departure of a team member, and involves selection of a replacement. However, since the focus of this paper is on team selection, subtraction that does not necessitate replacement is beyond the scope of this paper. 
Finally, this framework introduces a new conceptualization, i.e., sequential selection. It is adopted either when constraints prevent the selection of all team members simultaneously (termed constraint-driven in this paper) or when the task cannot be well defined at the outset and evolves over time (termed coevolution-driven). Thus this theorizing responds to scholars' calls for more attention to aspects like evolutionary states and path dependence in group dynamics (Cronin, 2015; Cronin, Weingart, \& Todorova, 2011).

The paper is organized in the following manner. The first section develops a definition of the team selection process construct. Then, the temporal team selection framework and the three temporal selection processes are described. Next, the arithmetic of change and temporal patterning constructs are applied to the three temporal selection processes. Finally, in the Discussion section, the contribution of this paper is summarized and its implications for theory and practice are delineated.

\section{The Team Selection Process}

Before proceeding, it is important to set out the boundary conditions of this theorizing. The focal unit of analysis is the (single) team. Thus with regard to multi-team systems (MTS) (Mathieu, Tannenbaum, Donsbach, \& Alliger, 2013) it will only be applicable to individual teams in the MTS and not to the MTS as a whole. Also, with regard to multiple team membership contexts (Maynard, Mathieu, Rapp, \& Gilson, 2012; O’Leary, Mortensen, \& Woolley, 2011) it will only be applicable to any given team composition at a point in time.

The team is defined as "(a) two or more individuals who (b) socially interact (face-toface or, increasingly, virtually); (c) possess one or more common goals; (d) are brought together to perform organizationally relevant tasks; (e) exhibit interdependence with respect to workflow, goals, and outcomes; (f) have different roles and responsibilities; and (g) are together embedded in an encompassing organizational system, with boundaries and linkages to the broader system context and task environment (Kozlowski \& Ilgen, 2006, p. 79).” 
Although the definition includes two-member teams, the minimum team size for this theorizing is three members, since "teams of three or more enable coalitions and related interpersonal interaction complexities that are absent in dyads" (Kozlowski \& Ilgen, 2006, p. 79). Also, since the focus is on selection, role-based temporary or flash teams with variable team membership, such as airline flight crews, and operating theatre teams (Tannenbaum, Mathieu, Salas, \& Cohen, 2012), are excluded.

This paper is consistent with recent work on team selection. Emergent work on team staffing has attempted to distinguish between selecting for new teams and for existing teams (e.g., Mathieu et al., 2013). This paper follows suit and includes both new teams (cf. naïve teams, Maynard \& Gilson, 2014) and existing teams (cf. intact teams, Elfenbein \& O'Reilly, 2007).

Although the term team selection process is not well defined in the management literature, there are several other terms such as 'models of team staffing' (e.g., Klimoski \& Jones, 1995; Klimoski \& Zukin, 1999; Orvis \& Zaccaro, 2008; Mohammed et al., 2010; Zaccaro \& DiRosa, 2012), which appear to be synonymous. Based on these, team selection process is defined as comprising the following six steps: (1) conduct a team task analysis; (2) establish team size; (3) identify the requisite knowledge, skills, attitudes, and other factors (KSAOs); (4) generate a pool of candidates for each position or vacancy being filled; (5) assess candidates; and (6) select team members. These steps and their mapping onto other models are shown in Table 1. As evident from Table 1, the team selection process defined in this paper is more comprehensive (six steps) than previous models (four or five steps).

Insert Table 1 about here 
The first step is to conduct a team task analysis (TTA). This step has been included in the three more recent extant models. According to Mohammed et al. (2010, p. 804), TTA "is a mechanism for capturing team task features through the systematic study and description of member jobs." It includes aspects such as identifying the activities needed to be carried out by the team (which are typically bifurcated into taskwork-related and teamwork-related), and then collecting data (through methods such as questionnaires, interviews, observation and critical incidents) to determine their order of relevancy (Mohammed et al., 2010; Zaccaro \& DiRosa, 2012).

The second step, i.e., establish team size, has been included in only two of the five extant models. This is surprising because group or team size is critical to performance (Steiner, 1972). According to Mohammed et al. (2010, p. 809), determining an appropriate team size is important because "too few members can result in unreasonable work demands and too many members can produce unnecessary redundancy."

In the third step, based on the TTA, the requisite KSAOs are identified. This step has been included in all five extant models. KSAOs at the individual-level include both taskworkrelated and teamwork-related, and in each case they can be further bifurcated into generic (cf. transportable, Zaccaro \& DiRosa, 2012) and specific. For instance, Goodwin (1999) examined the relationship of 15 predictor variables, which included five taskwork-generic abilities, three taskwork-specific skills, four teamwork-generic personality characteristics, and three teamwork-specific aspects.

The fourth step, i.e., generate pool of candidates for each position/vacancy being filled, has been included in only two of the extant models. According to Zaccaro and DiRosa (2012, p. 212), research on this aspect is "practically nonexistent." This step is particularly important because it focuses attention on casting the net wide so as to increase the likelihood of finding the right candidates. In the context of organizational teams, a key decision in this step would 
pertain to whether to conduct only an internal search or also include an external search (Zaccaro \& DiRosa, 2012). In non-organizational contexts, such as entrepreneurial teams, it would focus attention on searching beyond existing social relationships, such as friends, work colleagues, family, or sexual partners (Birley, 1985; Larson \& Starr, 1993).

The fifth and penultimate step involves assessing candidates on both taskwork-related and teamwork-related KSAOs, and has been included in all five previous models. Assessing candidates' taskwork-related KSAOs is similar to that carried out in organizational hiring (cf. personnel selection, Ployhart, 2006; Sackett \& Lievens, 2008). Teamwork-related KSAOs could be assessed through personality tests (Hogan \& Holland, 2003; LePine, Buckman, Crawford, \& Methot, 2011) or situational judgment tests that assess teamwork KSAOs (e.g., Stevens \& Campion, 1994, 1999), or measuring collectivism (Zaccaro \& DiRosa, 2012), or conducting structured interviews to assess candidates' social skills (Morgeson et al., 2005).

The sixth and final step, i.e., selecting the candidates has been included in all five previous models. Simply selecting those who score the highest on taskwork-related and teamwork-related KSAOs is suboptimal (Hollenbeck, DeRue, \& Guzzo, 2004; Klimoski \& Zukin, 1999; Zaccaro \& DiRosa, 2012). In a team selection context, "it is important to not only seek the best individuals for the team, but the best combination of individuals in terms of the mix" of KSAOs (Mohammed et al., 2010, p. 811) implying that unlike personnel selection which purely considers individual-level factors, team selection must consider factors at multiple levels, i.e., individual and team. This aspect has been emphasized in several research domains. Social psychologists posit that the configuration of member attributes in a team (cf. team composition, Levine \& Moreland, 1990) has important implications for team processes and outcomes. In the strategic human resource management (SHRM) research domain, Crocker and Eckardt (2013) in a study using Major League Baseball data showed that in team performance both individual-level and higher-level factors 
were important. This is similar to the famous Coleman's "bathtub" or "boat", in the strategy and organization theory literature (Felin, Foss, \& Ployhart, 2015), which figuratively depicts that higher-level outcomes are impacted not only by higher-level antecedents but also by individual-level actions (which could also be influenced by higher-level antecedents).

The six steps as described in this team selection process are all relevant when new teams are being staffed, with all team members being simultaneously selected. However, when new teams are being staffed over a longer period of time (termed sequential selection) or new team members are being selected to fill vacancies in an existing team (termed substitution selection), all six steps as described may not be relevant, as shown in Table 1 .

\section{The Temporal Team Selection Framework}

The fully staffed team construct is central to the temporal team selection framework and is therefore clarified prior to discussing the framework and its concomitant processes.

\section{Fully Staffed Team}

The fully staffed team construct has been implicit in the literature but to the best of my knowledge is articulated explicitly for the first time here. Although the concept of a 'fully staffed team' is naturally relevant in domains such as sports (e.g., McNamee, 2010) and medicine (e.g., Swensen et al., 2009), it has been somewhat neglected in the mainstream groups and teams literature. There have been notable exceptions in social psychology (i.e., Cini, Moreland, \& Levine, 1993) and entrepreneurship (e.g., Roure \& Maidique, 1986; Roure \& Keeley, 1990), which have focused on staffing levels in general. Cini et al. (1993) define the staffing level of a group as a comparison between how many individuals actually belong to the group, and how many are needed for optimal performance. In an entrepreneurship context Roure and Maidique (1986) define a complete team as a group that has a leader (i.e., the CEO) and heads of essential functions (i.e., marketing, engineering, finance, and operations). Forbes et al. (2006, p. 234, emphasis added) report that "the founder and his 
investors agreed that succeeding in this market required a fully staffed, functionally balanced management team."

A fully staffed team is one in which the essential roles required to complete the task are filled by the optimal number of members. This definition resonates with what Hudson and Shen (2015, p. 245) refer to as "a more refined definition" of understaffing, namely, "a situation in which there are too few employees to fulfill essential tasks and functions of a unit [emphasis added]." If the task changes (i.e., expands or contracts) such that the understanding of which roles or functions are deemed essential also changes, then the team may no longer be fully, i.e., optimally, staffed. It may be overstaffed, if the task has shrunk, or understaffed if it has expanded. The fully staffed team construct is fundamental to the team selection process since it provides the marker that distinguishes between new team formation and team member selection for ongoing teams as seen in Figure 1.

Insert Figure 1 about here

In Figure 1, the horizontal dimension (or X-axis) is linear time, and the vertical dimension (or Y-axis) is the number of selected team members. The point in time $\left(\mathrm{T}_{0}\right)$ when the team is fully staffed (marked on Y-axis). This signifies event time because, paraphrasing Ancona et al. (2001), people can use the selection event as a reference point for things that happen before and after. Substitution selection has been depicted to occur only after the team has been fully staffed, and though that is usually the case, in some sequential selection situations it is possible that one of the selected team members may quit and need to be replaced, necessitating substitution selection even before the team is fully staffed. Although not labeled as such, the longitudinal study by Van Oorschot, Akkermans, Sengupta, and Van Wassenhove (2013) provides evidence of simultaneous selection, constraint-driven sequential 
selection, coevolution-driven sequential selection, and substitution selection. The detailed characteristics of each of the three processes are presented in Table 2.

Insert Table 2 about here

\section{Simultaneous Selection}

Simultaneous selection (indicated by the dashed line in Figure 1) is defined as a team selection process for new teams in which all members are needed from the outset to perform the task, and are selected within a short span of time, i.e., hours, days, or even a few weeks (indicated by the distance of $-\mathrm{T}_{1}$ to $\mathrm{T}_{0}$ ). Hence, the decision-making complexity is relatively high compared to the other selection processes. Simultaneous selection is a single activity (Ancona et al., 2001) which encompasses multiple selection decisions. In this case both team tenure diversity, i.e., the distributional differences among members of a team with respect to their tenure in the team (Tyran \& Gibson, 2008), and individual tenure dissimilarity, i.e., the extent to which an individual's tenure in the team differs from that of others in his/her team (O’Reilly, Caldwell, \& Barnett, 1989; Pelled, Ledford, \& Mohrman, 1998), will be low. The group development processes (e.g., Tuckman, 1965) begin after the selection is complete.

All steps of the team selection process, as described, are relevant for simultaneous selection. This process is relevant for the widest variety of teams and hence it is not surprising that most of the scholarly work, particularly in OB and IO psychology has either explicitly or implicitly focused on this context. Simultaneous selection is similar to Mathieu et al's (2013) single team formation construct.

\section{Sequential Selection}

Sequential selection is defined as a team selection process for new teams in which members are selected and added to the team over a longer period of time, i.e., weeks, months, 
or sometimes even a year or two (cf. ramp-up phase, Van Oorschot et al., 2013). Since usually (but not necessarily) only one selection decision is being taken at a time, the decisionmaking is generally less complex than simultaneous selection, but because the team is not yet fully staffed (as is usually the case with substitution selection), it is more complex than substitution selection. Sequential selection is a repeated activity (Ancona et al., 2001) because the selection process is repeated for each selection and this usually occurs at irregular or unpredictable intervals. Therefore in this case, the team tenure diversity will be high and the individual tenure dissimilarity will be moderate. Further, the group development processes co-occur along with the selection process. Sequential selection is probably the least studied of the three contexts. There appears to be no theoretical literature on this topic (as indicated by the empty cell in Table 2), and the limited empirical literature resides in the entrepreneurship, and project management research streams.

Sequential selection is adopted either when constraints (such as inadequate funds, time, or candidates) inhibit the optimal staffing of the team (termed constraint-driven) or because the task itself evolves and the team evolves in response (termed coevolution-driven). These two variants of sequential selection are depicted in Figure 2.

\section{Insert Figure 2 about here}

As can be seen from Figure 2, in constraint-driven sequential selection, although the team task and the complement required to execute it are clear from the outset, constraints prevent the team from being fully staffed. However, in coevolution-driven sequential selection the task itself evolves, and as it evolves, the staffing requirements coevolve with it, and then the selection process is undertaken to fill that requirement. For instance, a dot-com entrepreneurship or new product development process could start with one person (i.e., the 
entrepreneur or ideator), then a programmer would be needed to develop the prototype, then a marketing expert would be needed to test the prototype with customers, fine-tune it and brand it, and then a finance professional would be needed to help prepare the business model and obtain financing. Thus only toward the end of each stage or phase, whose duration itself is not well defined, the staffing requirement for the next one becomes clear. In constraint-driven sequential selection the objective is team completion, whereas in coevolution-driven sequential selection it is team expansion, the team being fully staffed (or at least not necessarily understaffed) at each stage/phase.

Constraint-driven sequential selection. In this case, the team is understaffed from the time the team selection process begins $\left(-\mathrm{T}_{2}\right)$ until the time it is completed $\left(\mathrm{T}_{0}\right)$. All six steps as delineated in the team selection process are relevant in this case. However, in the third step, the requisite KSAOs need to be identified only for the position being filled as compared to all positions for simultaneous selection. Every addition to a team is crucial because it would impact team cognition structures, processes, and outcomes (Forbes et al., 2006). Further, as each member of the team is hired and the team becomes more complete, team composition (Levine \& Moreland, 1990) becomes an important consideration for subsequent selections. Hi-tech start-ups (Roure \& Keeley, 1990) would exemplify constraint-driven sequential selection. Constraint-driven sequential selection resonates with Beckman and Burton's (2008) team completeness construct.

Coevolution-driven sequential selection. In this case, the task evolves and results in the team being expanded, as depicted in Panel (B) of Figure 2. Unlike in constraint-driven sequential selection, the team is not necessarily understaffed during the selection process. As the task evolves it typically goes through stages which are marked by the addition of a team member. Thus the task and the team evolve together till the task (e.g., entrepreneurial venture) completes its evolution and reaches its steady-state fully staffed level $\left(\mathrm{T}_{0}\right)$. As 
alluded to, this is common in entrepreneurship in general (e.g., Forbes et al., 2006) and academic spin-offs in particular (see stage-of-growth models, Bjørnåli \& Gulbrandsen, 2010).

In the context of entrepreneurial teams, new member additions represent identifiable events in the team-formation process that are often conscious and deliberate actions by the team (Forbes et al., 2006). Vohora, Wright and Lockett (2004) investigated growth patterns in high-tech university spin-off ventures. They identified four 'critical junctures' and found that at two of these junctures the ventures required additional human capital, inter alia, to continue to develop. Similarly, Bjørnåli and Gulbrandsen (2010) found that adding board members was associated with the progress of an academic spin-off developing from one stage of development to another. However, while adding team members is critical, it may not always be beneficial. Chandler, Honig, and Wiklund (2005), in a panel study of 408 ventures, found evidence that adding team members was negatively associated with performance.

With regard to the team selection process, typically the first two steps, i.e., conduct a TTA and establish team size, may not be relevant (as shown in Table 1), since both task and team are evolving. Thus, the team selection process would have only four steps. The first step in this process would be the third step of the generic team selection process, i.e., identify requisite KSAOs. Similar to constraint-driven sequential selection, the requisite KSAOs would need to be identified only for the position being filled. Further, as each team member is added and the team becomes larger, even though its degree of completeness is indeterminate, team composition would become an increasingly relevant consideration for subsequent selections. The remaining three steps of the team selection process would be similar to that of the other temporal selection processes. (However, in case the road-map of task or project evolution is clear, it would imply that the additional tasks can be predicted and their impact on staffing can be estimated, then it would be similar to constraint-driven sequential selection and all six steps as indicated for that process would be relevant.) 


\section{Substitution Selection}

Substitution selection (indicated by the dashed-dotted line in Figure 1) is defined as a team selection process for selecting one or more new members to replace member/s who have exited the team. Thus, the objective in this case is to bring the team back to its pre-separation size. It is a single activity, and a single decision for each substitution.

Typically, the substitution selection begins at some point ( $\mathrm{T}_{1}$ in Figure 1$)$ after the team has been fully staffed when one or more team member/s exit/s the team either voluntarily or involuntarily. However, when the team is being formed through sequential selection it is possible that a team member could quit (and trigger a substitution selection process) even before the team is fully staffed. Like sequential selection, substitution selection has also been a relatively neglected aspect. According to Tannenbaum et al. $(2012$, p. 7$)$, "team composition research has not typically considered characteristics of leavers and joiners and how they change the relative mix of team member KSAOs."

With regard to the team selection process, it is similar to the coevolution-driven sequential selection process in that it is typically a four-step process where the first step corresponds to the third step of the generic team selection process, i.e., identify requisite KSAOs. In this case, the first two steps, i.e., establish team size and conduct a team task analysis, are usually not relevant (as shown in Table 1) since the team already exists. Once again, the requisite KSAOs would need to be identified only for the position/s being filled. Uniquely, in this case, because the position was previously filled, the characteristics of the leaver/s would influence the selection. If the departure was due to natural turnover, then the focus is likely to be on getting someone similar to the leaver (cf. supplementary fit, Werbel \& Johnson, 2001). However, if the exit/s were due to management's action, then the focus is likely to be on getting someone who is very dissimilar to the leaver/s, especially regarding their problematic attributes (cf. complementary fit, Werbel \& Johnson, 2001). 
Substitution selection is particularly relevant for teams such as boards of directors (e.g., Shivdasani \& Yermack, 1999; Westphal \& Zajac, 1995), long-standing work or management teams (Cohen \& Bailey, 1997), and entrepreneurial teams. According to Beckman, Burton, and O'Reilly (2007, p. 149), entrepreneurship scholars “acknowledge that the skills and capabilities required of the team members who lead entrepreneurial firms change over time; thus new team members need to be brought in and founders whose skills have become outmoded need to be replaced." In this context, assuming the team has been performing as a fully staffed team for a while (cf. late stage group, Funk \& Kulik, 2012), there would be a clear demarcation between the new hire/s and the rest of the team, implying an increase in both individual tenure dissimilarity and team tenure diversity. Further, in such cases the group development processes would be largely complete prior to the selection.

\section{Arithmetic of Team Selection Processes and their Temporal Patterning}

In this section I consider Arrow and McGrath's (1993) arithmetic of membership changes (i.e., addition, subtraction, and replacement) parsing the discussion around the central, fundamental event, i.e., fully staffed level. Thus I discuss membership changes during two time periods, i.e., up tothe fully staffed level, and after the fully staffed level. The theorizing in this section resonates with context-emergent turnover (CET) theory (Nyberg \& Ployhart, 2013 ) in the SHRM literature which "posits that the quantity and quality of turnover rates and replacement hires interact within a dynamic temporal system to influence unit performance" (Call, Nyberg, Ployhart, \& Weekley, 2015, p. 1208). For instance, Ployhart, Weekley, and Ramsey (2009) found that the flow of unit service orientation, which is based on membership change in a unit, had a positive but decreasing relationship with unit effectiveness.

There are several aspects of membership changes that would impact team performance such as magnitude of change, impetus of change, where the change occurs, inter alia, however in keeping with the time-centric orientation of this paper I focus on only one of 
them, i.e., temporal patterning (Arrow \& McGrath, 1993, 1995). Temporal patterning includes the following four aspects: (a) frequency of membership changes, (b) duration of periods of continuity, (c) regularity and predictability of changes, and (d) timing of change in relation to the life cycle of the group (Arrow \& McGrath, 1995). Life cycle models of group development "describe the process of change as the unfolding of a prescribed sequence of stages following a program that is immanent within or imposed upon the entity" (Arrow et al., 2004, p. 81).

The temporal patterning construct is similar to the time dispersion of turnover events (Hausknecht \& Holwerda, 2013) in the SHRM literature. Turnover event time dispersion is defined "as the distribution of turnover events across time" such that "high turnover distribution is when events are more evenly distributed; low turnover dispersion means that turnover events are clustered" (Call et al., 2015, p. 1213). Lower turnover dispersion is likely to produce a stronger shock to the HRM system, and adversely impact communication and coordination thereby having a greater negative impact on team performance (Call et al., 2015; Nyberg \& Ployhart, 2013).

In Table 3, I summarize the arithmetic of membership change, implications of membership events, prior to and after the fully staffed level, on temporal patterning (cumulatively from the start of the team selection process) and impact on team performance. Thus whereas the membership change is an event, i.e., occurs at a point in time, the temporal patterning is viewed from a longitudinal, linear time perspective.

Insert Table 3 about here

\section{Membership changes up toFully Staffed level}


During this period membership change would be a consequence of constraint-driven sequential selection (addition, by definition), and substitution selection (only if there is subtraction that requires replacement). In terms of temporal patterning, constraint-driven sequential selection would have high frequency of changes (i.e., additions). Further the timing of the changes would be unpredictable, since the additions depend on constraints being eased (e.g., next round of funding for new ventures) whose timing itself is not predictable. Hence the duration of continuity and the impact on the group life cycle and development processes would vary depending on the temporal distribution of the additions, and whether they were done singly or in groups. Thus, following Arrow and McGrath (1993), who posit that membership dynamics affect group performance, the relatively high frequency of membership changes during constraint-driven sequential selection would impact team performance. Further, the impact on team performance would depend on the sequential distribution of selections between core team members (whose roles are most important for team performance) and peripheral (i.e., non-core) team members (Humphrey, Morgeson, \& Mannor, 2009; Van Oorschot et al., 2013). Humphrey et al. (2009) found that factors such as high levels of experience and job-related skill were important compositional predictors of team performance, but the relationships between these factors and performance were significantly stronger when the characteristics were possessed by the core role holders. Building on this, what would be the impact on team processes and team performance if all core role holders were selected ahead of peripheral role holders, as compared to when one or more peripheral role holders were selected ahead of some core role holders? And if the former has a greater positive impact then would team leaders and selectors be well-advised to wait for every core position to be filled before selecting peripheral role holders? These questions could be explored in future research, particularly by applying sequence methods (Herndon \& Lewis, 2015). 
If team member/s quit prior to the team being fully staffed and need to be replaced it would increase the frequency of changes (by two for every replacement). This would further decrease the duration of periods of continuity. Also, since subtraction is usually not expected to occur prior to the fully staffed level these membership changes would further increase the unpredictability of the changes and result in greater disruption of group development processes and team performance. Once again, the distribution of the subtractions or turnover between core and peripheral team members would be relevant. Research suggests that replacing a core role-holder is more disruptive than replacing a peripheral role-holder (Summers et al., 2012). However if the core role-holder being replaced had a relatively short tenure in the team (because of being selected more recently) as compared to a peripheral roleholder being replaced who had a relatively long tenure in the team (because of being one of the first selected), it is not clear which would be more disruptive, and this could be explored in future research. Once again, the impact on coordination and team performance of various combinations of coreness (i.e. core or peripheral) and tenure (i.e., long or short) could be investigated using sequence methods (Herndon \& Lewis, 2015).

\section{Membership changes after Fully Staffed level}

During this period membership change would be a consequence of coevolution sequential selection (addition, by definition), and substitution selection (only if there is subtraction that requires replacement). Unlike simultaneous selection or constraint-driven sequential selection which may not need any additions after they reach the fully staffed level, in coevolution sequential selection at each stage the team is fully staffed, and team member addition implies task expansion and evolution which continues till it completes its evolution (e.g., the enterprise has been fully established and all senior management roles have been filled) and reaches its steady-state fully-staffed level. But unlike those in constraint-driven sequential selection, these additions would be more predictable, since they are triggered by 
milestones or phase completions (see sequential stage models, Arrow et al., 2004). Also, since the task evolves along with the team the membership changes could align better with group life cycle and development processes and therefore be relatively less disruptive as compared to constraint-driven sequential selection.

Substitution selection may take place if there is subtraction that requires replacement. If the team was formed by simultaneous selection then these would be the first membership changes (at least two, i.e., subtraction + addition, for every substitution) for the team. Hence the frequency of changes over the life of the team would be lower, ceteris paribus, than substitution selection that follows teams that have been formed by constraint-driven or coevolution sequential selection. However in all three cases of substitution selection (\#4. \#5, and \#6 in Table 3), the subtraction/s (and consequently the replacement/s) are generally not predictable and therefore the duration of periods of continuity would vary depending on the number and temporal distribution of the subtractions, and the number and temporal distribution of the replacements. Further, the timing of these changes (with regard to group life cycle and group development processes) and the relative impact of the disruption on team performance in each of the three scenarios (\#4, \#5, and \#6) would be hard to predict and could be examined in future research.

For instance, the impact on team performance would depend on the formation of the transactive memory system (TMS), which is "the shared division of cognitive labor with respect to encoding, storing, and retrieving knowledge from different domains (Lewis, Belliveau, Herndon, \& Keller, 2007, p. 160; see also Hollingshead, 2001; Wegner, 1986).” Future research could investigate whether a stronger TMS is formed through simultaneous selection or through sequential selection. And if a substitution selection occurs at a particular time after the fully staffed level, whether the TMS would be more disrupted, when the team 
was formed simultaneously or when it was formed sequentially, is a question that could also be investigated in future research.

The impact of membership changes would also depend on whether the role-holder being substituted was core or peripheral (Summers et al., 2012). It is likely that the departure of a core role-holder would impact the TMS more than that of a peripheral role-holder, but this would need to be empirically examined, because sometimes the latter could provide the vital glue or synapses amongst core role holders. Further, if two core role holders are substituted the relative impact on TMS (and team performance) between the two situations would depend on the closeness of the match between the departee's characteristics and his/her replacement's characteristics. For instance, Summers et al. (2012) found that the relative cognitive ability of the new member (compared to that of the departing or replaced member) was positively associated with levels of flux in coordination.

However, if there are unplanned subtractions (and their concomitant replacements) in a coevolution selection situation before the task evolution is complete (and steady-state level achieved), it could greatly disrupt aspects such as the TMS which would be coevolving with the team and the task. This suggests that the relative impact of substitution selection prior to the team reaching the steady-state fully staffed level would be higher than in the other two cases of substitution selection (\#4 and \#5 in Table 3). Future research could investigate this aspect. It could also investigate the relative impact on team processes and performance of substitution selection during the addition phase of constraint-driven sequential selection (\#2) and that during evolving stage (i.e., prior to the steady-state fully staffed level) of coevolution sequential selection (\#6).

\section{Discussion}

This paper responds to interdisciplinary calls for more research into the drivers of team composition by introducing an overarching temporal team selection framework that provides 
a synthesized coherence across disciplines such as OB, IO psychology, HRM, strategy, corporate governance, and entrepreneurship. The framework is fundamentally temporal and thus responds to calls for more time-centric scholarship, both in general, and with regard to teams in particular. By providing a temporal focus on team selection, this paper makes a contribution that is analogous to that of other papers with regard to team tasks (Bradley et al., 2003) and team processes (Marks et al., 2001).

The paper also introduces a new staffing construct, i.e., sequential selection, which has not been studied thus far. This is surprising because evolutionary models of team development (e.g., Cronin et al., 2011; Morgan, Salas, \& Glickman, 1993; Tuckman, 1965) have been established in the literature for quite a while. The two subtypes of sequential selection, i.e., constraint-driven and coevolution, are practised in domains such as entrepreneurship and project management and scholarship in these areas could examine the applicability of constructs such as TTA and KSAOs, which have been developed in the OB and IO psychology fields. Conversely, the latter fields could put greater focus on sequential models. This cross-pollination would naturally emerge from the synthesized coherence (Locke \& Golden-Biddle, 1997) that this paper develops. Sequential selection contexts would also be eminently amenable to the application of sequence methods, and lead to new insights about team temporal dynamics in these contexts (Herndon \& Lewis, 2015). In fact, in Herndon and Lewis' (2015) tabular comparison of traditional and sequence-based approaches, membership change is the first research domain listed, suggesting it is a prime candidate for appplying the latter approaches. As described earlier, sequence methods would be particularly useful in investigating the impact of various combinations or sequences of temporal patterning of selections and substitutions based on team members' attributes such core/peripherality or tenure. 
Apart from core/peripherality future research could investigate positional distribution, which is an SHRM construct that refers to "the degree to which departures are distributed across positions” (Hausknecht \& Holwerda, 2013, p. 213). Hale, Ployhart, and Shepherd (2016) found that positional distribution, i.e., whether the leaver was an employee or a manager, inter alia, influenced the consequences of the turnover event. However, it does not appear that time dispersion and positional distribution have been simultaneously investigated. Even recent theoretical work (Hausknecht \& Holwerda, 2013) develops separate propositions for time dispersion and positional distribution. Thus in future work the time dispersion (or temporal patterning) and the positional distribution could be jointly investigated using sequence methods (Herndon \& Lewis, 2015) among other methodologies.

Further, the framework makes salient key aspects of team staffing, such as the team selection process and fully staffed team which, although not new, have not been clearly articulated thus far in the mainstream group and organizational literature. Thus this paper also makes a contribution by providing clear and comprehensive definitions for both these constructs. Finally, this paper provides an indepth understanding of a subset of membership changes (Arrow \& McGrath, 1993, 1995), i.e., team member selection. By distinguishing between newcomer introduction through addition (i.e., sequential selection) and replacement (i.e., substitution selection), this paper helps address the issue that research that systematically compares the two is lacking (Rink, Kane, Ellemers, \& Van der Vegt, 2013).

\section{Future research}

In this paper I have focused only on face-to-face teams, but future work could apply this framework to virtual teams (VTs). VTs are "teams whose members use technology to varying degrees in working across locational, temporal, and relational boundaries to accomplish an interdependent task (Martins, Gilson, \& Maynard, 2004, p. 808).” Team size may affect VTs differently from face-to-face (FTF) teams since technology could mitigate the 
negative effects of team size (such as process losses and production blocking) and thereby facilitate larger teams, particularly with regard to tasks like brainstorming (Martins et al., 2004). Also, for VTs, the net could be cast really wide because, firstly, social media and the Internet could be harnessed to advertise the positions/vacancies to attract candidates in remote geographies as well, and secondly, if selected, these team members could work virtually from where they are based. Further, VTs are often conceptualized as having a more fluid membership than FTF teams (Martins et al., 2004) because specific expertise can be added or removed as tasks change (Alge, Wiethoff, \& Klein, 2003; Kirkman, Rosen, Tesluk, \& Gibson, 2004; also see virtual organizations, Lipnack \& Stamps, 1997; Wong \& Burton, 2000). It therefore appears that sequential selection (i.e., adding team members) and substitution selection (i.e., replacing team members) would be more prevalent in VTs as compared to FTF teams in general. These aspects along with other related issues could be investigated in future research.

Future work could also examine the role of temporal focus, "a temporal individual difference that captures the degree to which individuals characteristically devote their attention to the past, present, and future" (Nadkarni \& Chen, 2014, p. 1810), in the team selection processes. When selecting a team it may be logical to assume that decision-makers have a future focus, i.e., consider how the selected individuals will gel as a team and perform. But is this assumption valid, or would team selectors have a greater present focus in simultaneous selection, a greater future focus in sequential selection, and a greater past focus in substitution selection? These questions could be investigated in future research.

\section{Implications for Practice}

According to Mathieu et al. (2013, p. 533), "although the importance of getting teams right from the start is widely recognized, few organizations have processes or systems in place to make composition decisions ahead of time." This paper will create awareness among 
the practitioner community about the complexity of team selection decision-making, and the range of approaches and models that have been developed to address it. Further, even if one gets the team right (e.g., simultaneous selection), from the start, in a dynamic world where membership change is almost inevitable, it is important to get subsequent decisions (i.e., sequential selection or substitution selection) right as well.

Practitioners would realize that team member selection decision-making involves scenarios ranging in complexity from highly complex (simultaneous selection), to moderately complex (sequential selection), to relatively simple (substitution selection). Even though simultaneous selection is the most complex, selection in the other two contexts could have more significant implications than may appear at first sight. According to Forbes et al. (2006), the choice to add a member is important not only because it materially alters the available human capital but also because the manner in which the decision is made and implemented may have long-term implications.

With regard to sequential selection, it will make them aware of the dependence of later decisions on earlier ones, and should encourage them to take the time and make the effort to get those first selection decisions right. It will also make them aware of the consequences (both positive and negative) of new member addition. With regard to substitution selection, it would once again serve to highlight the consequences (both positive and negative) of member replacement, especially if the member is part of the 'core' of the team. Further, if the team has been performing for a long time prior to substitution selection, it would alert practitioners to the potential for significant disruption and they could steps to mitigate this, such as selecting someone who is demographically similar to the existing team members or ensuring adequate newcomer socialization takes place (Chen, 2005; Moreland \& Levine, 1988).

It appears that, similar to personnel selection (Ployhart, 2006), there is a gap between the research on team selection and its application by practitioners. This gap could be larger in 
non-organizational contexts since organizations may have the resources to fruitfully deploy the sophisticated instruments that IO psychologists have developed for team-related selection, which entrepreneurs might not have and who might therefore (sometimes unwittingly) resort to cognitive heuristics and biases (Parker, 2009; Pinto, 2014). The concept of the fully staffed team will make practitioners aware of this important marker, both with regard to team size/composition and team life cycle. It would presumably make them more cognizant of understaffing and overstaffing, both of which are problematic situations.

\section{Conclusions}

This paper develops a temporal team selection framework which encompasses three selection processes, i.e., simultaneous selection, sequential selection (which could be either constraint-driven or coevolution-driven), and substitution selection. This framework helps provide a synthesized coherence across diverse disciplines such as OB, IO psychology, entrepreneurship, and strategic management. The arithimetic of change is applied to these three selection processes particularly with regard to another time-based construct, i.e., temporal patterning. 


\section{References}

Alge, B. J., Wiethoff, C., \& Klein, H. J. (2003). When does the medium matter? Knowledgebuilding experiences and opportunities in decision-making teams. Organizational Behavior and Human Decision Processes, 91, 26-37.

Ancona, D. G., Okhuysen, G. A., \& Perlow, L. A. (2001). Taking time to integrate temporal research. Academy of Management Review, 26, 512-529.

Arrow, H., \& McGrath, J. E. (1993). Membership matters: How member change and continuity affect small group structure, process, and performance. Small Group Research, 24, 334-361.

Arrow, H., \& McGrath, J. E. (1995). Membership dynamics in groups at work: A theoretical framework. Research in organizational behavior, 17, 373-373.

Arrow, H., Poole, M.S., Henry, K.B., Wheelan, S., \& Moreland, R. (2004). Time, change, and development: The temporal perspective on groups. Small Group Research, 35, 73 105.

Ballard, D.I., Tschan, F., \& Waller, M.J. (2008). All in the timing: Considering time at multiple stages of group research. Small Group Research, 39, 328-351.

Beckman, C. M., Burton, M. D., \& O'Reilly, C. (2007). Early teams: The impact of team demography on VC financing and going public. Journal of Business Venturing, 22, 147 173.

Beckman, C. M., \& Burton, M. D. (2008). Founding the future: Path dependence in the evolution of top management teams from founding to IPO. Organization Science, 19, 3 24.

Bjørnåli, E., \& Gulbrandsen, M. (2010). Exploring board formation and evolution of board composition in academic spin-offs. The Journal of Technology Transfer, 35, 92-112.

Birley, S. (1985). The role of networks in entrepreneurial process. Journal of Business Venturing, 1, 107-117.

Bradley, J., White, B. J., \& Mennecke, B. E. (2003). Teams and tasks: A temporal framework for the effects of interpersonal interventions on team performance. Small Group Research, 34, 353-387. 
Call, M.L., Nyberg, A.J., Ployhart, R.E., \& Weekley, J. (2015). The dynamic nature of collective turnover and unit performance: The impact of time, quality, and replacements. Academy of Management Journal, 58, 1208-1232.

Chandler, G. N., Honig, B., \& Wiklund, J. (2005). Antecedents, moderators, and performance consequences of membership change in new venture teams. Journal of Business Venturing, 20, 705-725.

Chen, G. (2005). Newcomer adaptation in teams: Multilevel antecedents and outcomes. Academy of Management Journal, 48, 101-116.

Cini, M. A., Moreland, R. L., \& Levine, J. M. (1993). Group staffing levels and responses to prospective and new group members. Journal of Personality and Social Psychology, 65, 723-734.

Cohen, S. G., \& Bailey, D. E. (1997). What makes teams work: Group effectiveness research from the shop floor to the executive suite. Journal of Management, 23, 239-290.

Conger, J., \& Lawler, E. (2001). Building a high-performing board: How to choose the right members. Business Strategy Review, 12, 11-19.

Connerley, M. L., \& Mael, F. A. (2001). The importance and invasiveness of student team selection criteria. Journal of Management Education, 25, 471-494.

Crocker, A., \& Eckardt, R. (2013). A multilevel investigation of individual- and unit-level human capital complementarities. Journal of Management, 40, 509-530.

Cronin, M.A. (2015). Advancing the science of dynamics in groups and teams. Organizational Psychology Review, 5, 267-269.

Cronin, M. A., Weingart, L. R., \& Todorova, G. (2011). Dynamics in groups: Are we there yet? Academy of Management Annals, 5, 571-612.

Crossan, M., Cunha, M. P., Vera, D., \& Cunha, J. (2005). Time and organizational improvisation. Academy of Management Review, 30, 129-145.

Elfenbein, H. A., \& O’Reilly, C. A. (2007). Fitting in: The effects of relational demography and person-culture fit on group process and performance. Group \& Organization Management, 32, 109-142.

Felin, T., Foss, N.J., \& Ployhart, R.E. (2015). The microfoundations movement in strategy and organization theory. The Academy of Management Annals, 9, 575-632. 
Forbes, D. P., Borchert, P. S., Zellmer-Bruhn, M. E., \& Sapienza, H. J. (2006).

Entrepreneurial team formation: An exploration of new member addition.

Entrepreneurship Theory \& Practice, 30, 225-248.

Forster, W., \& Jansen, K. (2010). Co-creating new ventures: Attraction, search, and uncertainty in founding partnership formation. Frontiers of Entrepreneurship Research, 30, 1-15. Available at: http://digitalknowledge.babson.edu/fer/vol30/iss 10/2

Funk, C. A., \& Kulik, B. W. (2012). Happily ever after: Toward a theory of late stage group performance. Group \& Organization Management, 37, 36-66.

George, J. M., \& Jones, G. R. (2000). The role of time in theory and theory building. Journal of Management, 26, 657-684.

Goodwin, G. F. (1999). Predicting performance in U. S. Army Special Forces teams: Staffing and composition issues. Unpublished doctoral dissertation. The Pennsylvania State University.

Hausknecht, J.P., \& Holwerda, J.A. (2013). When does employee turnover matter? Dynamic member configurations, productive capacity, and collective performance. Organization Science, 24, 210-225.

Hale, D., Ployhart, R.E., \& Shepherd, W. (2016). A two-phase longitudinal model of a turnover event: Disruption, recovery rates, and moderators of collective performance. Academy of Management Journal, 59, 906-929.

Henneke, D., \& Luthje, C. (2007). Interdisciplinary heterogeneity as a catalyst for product innovativeness of entrepreneurial teams. Creativity and Innovation Management, 16, 121132.

Herndon, B., \& Lewis, K. (2015). Applying sequence methods to the study of team temporal dynamics. Organizational Psychology Review, 5, 318-332.

Hogan, J., \& Holland, B. (2003). Using theory to evaluate personality and job-performance relations: A socioanalytic perspective. Journal of Applied Psychology, 88, 100-112.

Hollenbeck, J. R., DeRue, D. S., \& Guzzo, R. (2004). Bridging the gap between I/O and research and HR practice: Improving team composition, team training, and team task design. Human Resource Management, 43, 353-366. 
Hollingshead, A.B. (2001). Cognitive interdependence and convergent expectations in transactive memory. Journal of Personality and Social Psychology, 81, 1080-1089.

Hudson, C.K., \& Shen, W. (2015). Understaffing: An under-researched phenomenon. Organizational Psychology Review, 5, 244-263.

Humphrey, S. E., Morgeson, F. P., \& Mannor, M. J. (2009). Developing a theory of the strategic core of teams: A role composition model of team performance. Journal of Applied Psychology, 94, 48-61.

Ilgen, D. R., Hollenbeck, J. R., Johnson, M., \& Jundt, D. (2005). Teams in organizations: From Input-Process-Output Models to IMOI Models. Annual Review of Psychology, 56, 517-543.

Kichuk, S. L., \& Wiesner, W. H. (1997). The big five personality factors and team performance: implications for selecting successful product design teams. Journal of Engineering and Technology Management, 14, 195-221.

Kirkman, B. L., Rosen, B., Tesluk, P. E., \& Gibson, C. B. (2004). The impact of team empowerment on virtual team performance: The moderating role of face-to-face interaction. Academy of Management Journal, 47, 175-192.

Klimoski, R., \& Jones, R. G. (1995). Staffing for effective group decision making: Key issues in matching people and task. In R. A. Guzzo \& E. Salas (Eds.), Team Effectiveness and Decision Making in Organizations (pp. 292-332). San Francisco: Jossey-Bass.

Klimoski, R. J., \& Zukin, L. B. (1999). Selection and staffing for team effectiveness. In E. Sundstrom (Ed.), Supporting Work Team Effectiveness (pp. 63-94). San Francisco: Jossey-Bass.

Kozlowski, S. W. J., \& Ilgen, D. R. (2006). Enhancing the effectiveness of work groups and teams. Psychological Science in the Public Interest, 7, 77-124.

Larson, A., \& Starr, J. A. (1993). A network model of organization formation. Entrepreneurship Theory and Practice, 17, 5-15.

LePine, J.A., Buckman, B.R., Crawford, E.R., \& Methot, J.R. (2011). A review of research on personality in teams: Accounting for pathways spanning levels of theory and analysis. Human Resource Management Review, 21, 311-330. 
Levine, J. M., \& Moreland, R. L. (1990). Progress in small group research. Annual Review of Psychology, 41, 585-634.

Lewis, K., Belliveau, M., Herndon, B., \& Keller, J. (2007). Group cognition, membership change, and performance: Investigating the benefits and detriments of collective knowledge. Organizational Behavior and Human Decision Processes, 103, 159-178.

Locke, K., \& Golden-Biddle, K. (1997). Constructing opportunities for contribution: Structuring intertextual coherence and "problematizing" in organizational studies. Academy of Management Journal, 40, 1023-1062.

Lipnack, J. \& Stamps, J. (1997). Virtual Teams: Reaching across space, time and organizations with technology. New York: John Wiley \& Sons.

Marks, M. A., Mathieu, J. E., \& Zaccaro, S. J. (2001). A temporally based framework and taxonomy of team processes. Academy of Management Review, 26, 356-376.

Martins, L. L., Gilson, L. L., \& Maynard, M. T. (2004) Virtual teams: What do we know and where do we go from here? Journal of Management, 6, 805-835.

Mathieu, J. E., Maynard, M. T., Rapp, T. L., \& Gilson, L. L. (2008). Team effectiveness 1997-2007: A review of recent advancements and a glimpse into the future. Journal of Management, 34, 410-476.

Mathieu, J. E., Tannenbaum, S. I., Donsbach, J. S., \& Alliger, G. M. (2013). Achieving optimal team composition for success. In E. Salas (Ed.), Developing and enhancing highperformance teams: Evidence-based practices and advice: 520-551. San Francisco: Jossey-Bass.

Maynard, M. T., \& Gilson, L. L. (2014). The role of shared mental model development in understanding virtual team effectiveness. Group \& Organization Management, 39, 13-32.

Maynard, M. T., Mathieu, J. E., Rapp, T. L., \& Gilson, L. L. (2012). Something(s) old and something(s) new: Modeling drivers of global virtual team effectiveness. Journal of Organizational Behavior, 33, 342-365.

McNamee, M. (2010). Rules, fairness, and the apparent duty to entertain in professional commodified sport. Sports, Ethics, and Philosophy, 4, 235-238. 
Mohammed, S., Cannon-Bowers, J., \& Foo, S. C. (2010). Selection for team membership: A contingency and multilevel perspective. In J. L. Farr \& N. T. Tippins (Eds.) Handbook of Employee Selection (pp. 801-822). New York: Routledge.

Mohammed, S., Mathieu, J. E., \& Bartlett, A. L. (2002). Technical-administrative task performance, leadership task performance, and contextual performance: considering the influence of team- and task-related composition variables. Journal of Organizational Behavior, 23, 795-814.

Moreland, R. L., \& Levine, J. M. (1988). Group dynamics over time: Development and socialization in small groups. In J. E. McGrath (Ed.), The social psychology of time: New perspectives. (pp. 151-181). Newbury Park, CA: Sage.

Moreland, R. L., \& Levine, J. M. (2003). Group composition: Explaining similarities and differences among group members. In M. A. Hogg \& J. Cooper (Eds.), The Sage handbook of social psychology (pp. 367-380). London: Sage.

Morgan, B. B., Salas, E., \& Glickman, A. S. (1993). An analysis of team evolution and maturation. Journal of General Psychology, 120, 277-291.

Morgeson, F. P., Reider, M. H., \& Campion, M. A. (2005). Selecting individuals in team settings: The importance of social skills, personality characteristics, and teamwork knowledge. Personnel Psychology, 58, 583-611.

Munyon, T. P., Summers, J. K., \& Ferris, G. R. (2011). Team staffing in modes in organizations: Strategic considerations on individual and cluster hiring approaches. Human Resource Management Review, 21, 228-242.

Nadkarni, S., \& Chen, J. (2014). Bridging yesterday, today, and tomorrow: CEO temporal focus, environmental dynamism, and rate of new product introduction. Academy of Management Journal, 57, 1810-1833.

Nyberg, A.J., \& Ployhart, R.E. (2013). Context-emergent collective turnover (CET) theory: A theory of collective turnover. Academy of Management Review, 38, 1-23.

O'Leary, M. B., Mortensen, M., \& Woolley, A. W. (2011). Multiple team membership: A theoretical model of its effects on productivity and learning for individuals and teams. Academy of Management Review, 36, 461-478.

O’Reilly, C., Caldwell, D., \& Barnett, W. (1989). Work group demography, social integration, and turnover. Administrative Science Quarterly, 34, 21-37. 
Orvis, K. L., \& Zaccaro, S. J. (2008). Team composition and member selection: Optimizing teams for virtual collaboration. In J. Nemiro, M. M. Beyerlein, L. Bradley, \& S. Beyerlein (Eds.), The Handbook of High-Performance Virtual Teams: A Toolkit for Collaborating across Boundaries (pp. 243-62). San Francisco, CA: Jossey-Bass.

Parker, S. C. (2009). Can cognitive biases explain venture team homophily? Strategic Entrepreneurship Journal, 3, 67-83.

Pelled, L. H., Ledford, G. E., \& Mohrman, S. A. (1998). Individual demographic dissimilarity and organizational inclusion: A field investigation. In Best Paper Proceedings, Academy of Management Annual Meeting, San Diego, CA.

Pinto, J. (2014). Entrepreneurs' cognitive biases and heuristics in entrepreneurial team recruitment. In Best Paper Proceedings, Academy of Management Annual Meeting, Philadelphia, PA.

Ployhart, R. E. (2006). Staffing in the $21^{\text {st }}$ Century: New challenges and strategic opportunities. Journal of Management, 32, 868-897.

Ployhart, R.E., Weekley, J.A., \& Ramsey, J. (2009). The consequences of human resource stocks and flows: A longitudinal examination of unit service orientation and unit effectiveness. Academy of Management Journal, 32, 996-1015.

Rink, F., Kane, A. A., Ellemers, N., \& Van der Vegt, G. (2013). Team receptivity to newcomers: Five decades of evidence and future research themes. The Academy of Management Annals, 7, 247-293.

Roe, R. A., Gockel, C., \& Meyer, B. (2012). Time and change in teams: Where we are and where are moving. European Journal of Work and Organizational Psychology, 21, 629656.

Roure, J. B., \& Keeley, R. H. (1990). Predictors of success in new technology based ventures. Journal of Business Venturing, 5, 201-220.

Roure, J. B., \& Maidique, M. A. (1986). Linking prefunding factors and high-technology venture success: An exploratory study. Journal of Business Venturing, 1, 295-306.

Sackett, P. R., \& Lievens, F. (2008). Personnel selection. Annual Review of Psychology, 59, 419-450. 
Shivdasani, A., \& Yermack, D. (1999). CEO involvement in the selection of new board members: An empirical analysis. Journal of Finance, 54, 1829-1853.

Sonnentag, S. (2012). Time in organizational research: Catching up on a long neglected topic in order to improve theory. Organizational Psychology Review, 2, 361-368.

Steiner, I.D. (1972). Group processes and productivity. New York: Academic Press.

Stevens, M. J., \& Campion, M. A. (1994). The knowledge, skill, and ability requirements for team-work. Implications for human resource management. Journal of Management, 20, 503-530.

Stevens, M. J., \& Campion, M. A. (1999). Staffing work teams: Development and validation of a selection test for teamwork settings. Journal of Management, 25, 207-228.

Summers, J.K., Humphrey, S.E., \& Ferris, G.R. (2012). Team member change, flux in coordination, and performance: Effects of strategic core roles, information transfer, and cognitive ability. Academy of Management Journal, 55, 314-338.

Swensen, S. J., Dilling, J. A., Milliner, D.S., Zimmerman, R. S., Maples, W. J., Lindsay, M. E., \& Bartley, G. B. (2009). Quality: The Mayo Clinic Approach. American Journal of Medical Quality, 24, 428-440.

Tannenbaum, S. I., Mathieu, J. E., Salas, E., \& Cohen, D. (2012). Teams are changing: Are research and practice evolving fast enough? Industrial and Organizational Psychology, 5, $2-24$

Tuckman, B. W. (1965). Development sequence in small groups. Psychological Bulletin, 63, 384-399.

Tyran, K. L., \& Gibson, C. B. (2008). Is what you see, what you get? The relationship among surface-and deep-level heterogeneity characteristics, group efficacy, and team reputation. Group \& Organization Management, 33, 46-76.

Van Oorschot, K. E., Akkermans, H., Sengupta, K., \& Van Wassenhove, L. N. (2013). Anatomy of a decision trap in complex new product development projects. Academy of Management Journal, 56, 285-307.

Vinkenburg, C. J., Jansen, P. G. W., Dries, N. \& Pepermans, R. (2014). Arena: A critical conceptual framework of top management selection. Group \& Organization Management, 39, 33-68. 
Vohora, A., Wright, M., \& Lockett, A. (2004). Critical junctures in the development of university high-tech spinout companies. Research Policy, 33, 147-175.

Wegner, D. (1986). Transactive memory: A contemporary analysis of the group mind. In G. Mullen \& G. Goethals (Eds.), Theories of group behavior (pp. 185-208). New York: Springer-Verlag.

Werbel, J. D., \& Johnson, D. J. (2001). The use of person-group fit for employment selection: A missing link in person-environment fit. Human Resource Management, 40, 227-240.

Westphal, J. D., \& Zajac, E. J. (1995). Who shall govern? CEO/Board power, demographic similarity, and new director selection. Administrative Science Quarterly, 40, 60-83.

Wong, S-S. \& Burton, R. M. (2000). Virtual Teams: What are their characteristics, and impact on team performance. Computational \& Mathematical Organization Theory, 6 , 339-360.

Zaccaro, S. J., \& DiRosa, G. A. (2012). The processes of team staffing: A review of relevant studies. International Review of Industrial and Organizational Psychology, 27, 197-229. 
Table 1: Team Selection Process

\begin{tabular}{|c|c|c|c|c|c|c|c|c|c|c|}
\hline \multirow{3}{*}{$\#$} & \multirow{3}{*}{ Team Selection Process Steps } & \multirow{3}{*}{$\begin{array}{c}\text { Klimoski \& } \\
\text { Jones } \\
\text { (1995) }\end{array}$} & \multirow{3}{*}{$\begin{array}{c}\text { Klimoski \& } \\
\text { Zukin } \\
\text { (1999) }\end{array}$} & \multirow{3}{*}{$\begin{array}{c}\text { Orvis \& } \\
\text { Zaccaro } \\
\text { (2008) }\end{array}$} & \multirow{3}{*}{$\begin{array}{l}\text { Mohammed } \\
\text { et al. (2010) }\end{array}$} & \multirow{3}{*}{$\begin{array}{c}\text { Zaccaro \& } \\
\text { DiRosa } \\
\text { (2012) }\end{array}$} & \multicolumn{4}{|c|}{ This paper } \\
\hline & & & & & & & \multirow{2}{*}{$\begin{array}{l}\text { Simul- } \\
\text { taneous } \\
\text { Selection }\end{array}$} & \multicolumn{2}{|c|}{ Sequential Selection } & \multirow{2}{*}{$\begin{array}{l}\text { Substi- } \\
\text { tution } \\
\text { Selection }\end{array}$} \\
\hline & & & & & & & & $\begin{array}{l}\text { Constraint- } \\
\text { driven }\end{array}$ & $\begin{array}{c}\text { Co- } \\
\text { evolution }\end{array}$ & \\
\hline 1 & Conduct a team task analysis & & & $\checkmark$ & $\checkmark$ & $\checkmark$ & $\checkmark$ & $\checkmark$ & $\begin{array}{l}\text { X Task } \\
\text { itself } \\
\text { evolves }\end{array}$ & $\begin{array}{c}\text { X Team } \\
\text { usually } \\
\text { exists }\end{array}$ \\
\hline 2 & Establish team size & $\checkmark$ & & & $\checkmark$ & & $\checkmark$ & $\checkmark$ & $\begin{array}{l}\text { X Evolves } \\
\text { with task }\end{array}$ & $\begin{array}{c}\text { X Team } \\
\text { usually } \\
\text { exists }\end{array}$ \\
\hline 3 & Identify requisite KSAOs & $\checkmark$ & $\checkmark$ & $\checkmark$ & $\checkmark$ & $\checkmark$ & $\checkmark$ & $\begin{array}{c}\checkmark \text { For } \\
\text { position/s } \\
(\text { filled })\end{array}$ & $\begin{array}{c}\checkmark \text { For } \\
\text { position/s } \\
\text { (added) }\end{array}$ & $\begin{array}{c}\checkmark \text { For } \\
\text { vacancies }\end{array}$ \\
\hline 4 & $\begin{array}{l}\text { Generate pool of candidates for } \\
\text { each position/vacancy being filled }\end{array}$ & & $\checkmark$ & & & $\checkmark$ & $\checkmark$ & $\checkmark$ & $\checkmark$ & $\checkmark$ \\
\hline 5 & Assess candidates & $\checkmark$ & $\checkmark$ & $\checkmark$ & $\checkmark$ & $\checkmark$ & $\checkmark$ & $\checkmark$ & $\checkmark$ & $\checkmark$ \\
\hline \multirow[t]{2}{*}{6} & Select team member/s & $\checkmark$ & $\checkmark$ & $\checkmark$ & $\checkmark$ & $\checkmark$ & $\checkmark$ & $\checkmark$ & $\checkmark$ & $\checkmark$ \\
\hline & \# of Steps & 4 & 4 & 4 & 5 & 5 & 6 & 6 & 4 & 4 \\
\hline
\end{tabular}


Table 2: Comparison of Three Temporal Team Selection Processes

\begin{tabular}{|c|c|c|c|c|}
\hline \multirow{2}{*}{ Attributes } & \multirow{2}{*}{ Simultaneous Selection } & \multicolumn{2}{|c|}{ Sequential Selection } & \multirow{2}{*}{ Substitution Selection } \\
\hline & & Constraint-driven & Coevolution-driven & \\
\hline New or existing teams? & New & New & New & Existing \\
\hline Team task & Static & Static & Dynamic & Static \\
\hline Team size & Static & Static & Dynamic & Static \\
\hline Fully staffed team construct & Relevant & Relevant & Not relevant & Usually relevant \\
\hline Objective & Team formation & Team completion & Team expansion & Team size maintenance \\
\hline Team performance & Begins only after selection & Concurrent with selections & Concurrent with selections & On-going prior to selection \\
\hline Number of decisions & Several, simultaneously & Usually one at a time & Usually one at a time & $\begin{array}{c}\text { Depends on exits, usually one } \\
\text { at a time }\end{array}$ \\
\hline Mapping activity to time & Single activity & Repeated activity & Repeated activity & Single activity \\
\hline Time period & Typically short & Typically long & Typically long & Relatively short \\
\hline Decision-making complexity & Relatively high & Moderate & Moderate & Relatively low \\
\hline Team tenure diversity & Low & High & High & Moderate \\
\hline Individual tenure dissimilarity & Low & Moderate & Moderate & High (potentially) \\
\hline Team development processes & Begin after selection & Occur along with selection & Occur along with selection & $\begin{array}{c}\text { Could be largely concluded } \\
\text { prior to selection }\end{array}$ \\
\hline Examples of types of teams & $\begin{array}{l}\text { Product design teams } \\
\text { (Kichuk \& Wiesner, 1997) }\end{array}$ & $\begin{array}{l}\text { Hi-tech start-ups (Roure \& Keeley, } \\
\text { 1990) }\end{array}$ & $\begin{array}{l}\text { Academic spin-offs (Bjørnåli \& } \\
\text { Gulbrandsen, 2010) }\end{array}$ & $\begin{array}{c}\text { Work and management teams } \\
\text { (Cohen \& Bailey, 1997); Board } \\
\text { of directors (Westphal \& Zajac, } \\
\text { 1995) }\end{array}$ \\
\hline $\begin{array}{l}\text { Representative theoretical } \\
\text { constructs/literature }\end{array}$ & $\begin{array}{l}\text { Single team formation } \\
\text { (Mathieu et al., 2013) }\end{array}$ & & $\begin{array}{l}\text { New member addition } \\
\text { (Forbes et al., 2006) }\end{array}$ & $\begin{array}{l}\text { The arena (Vinkenburg et al., } \\
\text { 2014) }\end{array}$ \\
\hline $\begin{array}{l}\text { Representative empirical } \\
\text { constructs/literature }\end{array}$ & $\begin{array}{c}\text { Selecting individuals in } \\
\text { team settings (Morgeson et } \\
\text { al., 2005) }\end{array}$ & $\begin{array}{c}\text { Team completeness (Beckman \& } \\
\text { Burton, 2008) }\end{array}$ & $\begin{array}{c}\text { Founding partnership } \\
\text { formation (Forster \& Jansen, } \\
\text { 2010) }\end{array}$ & $\begin{array}{c}\text { Selection of new board } \\
\text { members (Shivdasani \& } \\
\text { Yermack, 1999) }\end{array}$ \\
\hline Typical literature domains & OB, IO Psychology & $\begin{array}{c}\text { Entrepreneurship, Project } \\
\text { Management }\end{array}$ & Entrepreneurship & Strategic Management \\
\hline
\end{tabular}


Table 3: Arithmetic of Team Selection Processes, Temporal Patterning, and Impact on Team Performance

\begin{tabular}{|c|c|c|c|c|c|c|c|}
\hline \multirow[b]{2}{*}{ \# } & \multirow[b]{2}{*}{ Period } & \multirow[b]{2}{*}{\begin{tabular}{|c|}
$\begin{array}{c}\text { Team Selection } \\
\text { Process }\end{array}$ \\
\end{tabular}} & \multicolumn{4}{|c|}{ Temporal Patterning - Cumulative from the start of the team selection process } & \multirow[b]{2}{*}{ Impact on Team Performance } \\
\hline & & & Frequency of changes & $\begin{array}{c}\text { Duration of periods of } \\
\text { continuity }\end{array}$ & $\begin{array}{c}\text { Regularity/Predictability } \\
\text { of changes }\end{array}$ & $\begin{array}{c}\text { Timing of change with } \\
\text { regard to group life cycle }\end{array}$ & \\
\hline \multicolumn{8}{|c|}{ Upto Fully Staffed level } \\
\hline 1 & Addition & $\begin{array}{c}\text { Constraint-driven } \\
\text { sequential } \\
\text { selection }\end{array}$ & Relatively high & $\begin{array}{c}\text { Varies, based on number } \\
\text { and temporal distribution } \\
\text { of additions }\end{array}$ & $\begin{array}{l}\text { Less regular/predictable } \\
\text { than coevolution } \\
\text { sequential selection }\end{array}$ & $\begin{array}{c}\begin{array}{c}\text { Varies, based on number \& } \\
\text { temporal distribution of } \\
\text { additions, whether singly } \\
\text { or in groups }\end{array} \\
\end{array}$ & $\begin{array}{l}\text { Membership dynamics would } \\
\text { disrupt team performance }\end{array}$ \\
\hline \multicolumn{8}{|c|}{ Subtraction } \\
\hline 2 & Replacement & $\begin{array}{l}\text { Substitution } \\
\text { selection }\end{array}$ & $\begin{array}{l}\text { Implies at least } 2 \text { more } \\
\text { membership changes } \\
\text { (subtraction + addition) } \\
\text { hence higher than \#1 }\end{array}$ & $\begin{array}{c}2 \text { more membership } \\
\text { changes hence shortens } \\
\text { periods of continuity in } \# 1\end{array}$ & \begin{tabular}{|c|} 
Typically no subtraction \\
expected prior to fully \\
staffing hence even less \\
predictable than \#1
\end{tabular} & $\begin{array}{l}\text { Will have greater impact } \\
\text { on group development } \\
\text { processes than in } \# 1\end{array}$ & Even more disruptive than \#1 \\
\hline \multicolumn{8}{|c|}{ After Fully Staffed level } \\
\hline 3 & Addition & $\begin{array}{l}\text { Coevolution } \\
\text { sequential } \\
\text { selection }\end{array}$ & $\begin{array}{c}\text { Typically higher than } \\
\text { simultaneous selection } \\
\text { and constraint-driven } \\
\text { selection }\end{array}$ & $\begin{array}{l}\text { Varies, depending on the } \\
\text { length of time of each } \\
\text { phase of task evolution }\end{array}$ & $\begin{array}{c}\text { More regular/predictable } \\
\text { than constraint-driven } \\
\text { selection }\end{array}$ & $\begin{array}{c}\text { More aligned with group } \\
\text { life cycle as task and team } \\
\text { evolve together }\end{array}$ & $\begin{array}{l}\text { Less disruptive than } \\
\text { constraint-driven selection }\end{array}$ \\
\hline \multicolumn{8}{|c|}{$\begin{array}{l}\text { Subtraction after team is fully staffed through: } \\
\text { - Simultaneous selection } \\
\text { - Constraint-driven sequential selection } \\
\text { - Coevolution sequential selection }\end{array}$} \\
\hline \multicolumn{8}{|c|}{ Replacement after team is fully staffed through: } \\
\hline 4 & $\begin{array}{l}\text { - Simultaneous } \\
\text { selection }\end{array}$ & $\begin{array}{l}\text { Substitution } \\
\text { selection }\end{array}$ & $\begin{array}{l}\text { Would be first two } \\
\text { membership changes (-, } \\
+ \text { ) hence would be lower } \\
\text { than \#5 and \#6 }\end{array}$ & $\begin{array}{l}\text { Varies, based on number } \\
\text { \& temporal distribution } \\
\text { of subtractions, and time } \\
\text { for replacements }\end{array}$ & Not predictable & $\begin{array}{l}\text { Varies, based on how soon } \\
\text { or late after formation the } \\
\quad \text { exit/s take place }\end{array}$ & $\begin{array}{c}\text { Could be more, or less, } \\
\text { disruptive than } \# 5\end{array}$ \\
\hline 5 & $\begin{array}{l}\text { - Constraint- } \\
\text { driven sequential } \\
\text { selection }\end{array}$ & $\begin{array}{l}\text { Substitution } \\
\text { selection }\end{array}$ & $\begin{array}{l}\text { Would add } 2 \text { changes to } \\
\text { those in reaching Fully } \\
\text { Staffed level hence } \\
\text { higher than \#4 }\end{array}$ & $\begin{array}{c}\text { Varies, based on number } \\
\& \text { temporal distribution } \\
\text { of subtractions, and time } \\
\text { for replacements }\end{array}$ & Not predictable & $\begin{array}{l}\text { Varies, based on how soon } \\
\text { or late after Fully Staffed } \\
\text { level the exit/s take place }\end{array}$ & $\begin{array}{c}\text { Could be more, or less, } \\
\text { disruptive than } \# 4\end{array}$ \\
\hline 6 & $\begin{array}{l}\text { - Coevolution } \\
\text { sequential } \\
\text { selection }\end{array}$ & $\begin{array}{l}\text { Substitution } \\
\text { selection }\end{array}$ & $\begin{array}{l}\text { Would add } 2 \text { changes to } \\
\text { those during evolution } \\
\text { hence higher than \#4 }\end{array}$ & $\begin{array}{c}\text { Varies, based on number } \\
\& \text { temporal distribution } \\
\text { of subtractions, and time } \\
\text { for replacements }\end{array}$ & Not predictable & $\begin{array}{l}\text { If changes occur prior to } \\
\text { steady-state level it could } \\
\text { greatly disrupt group } \\
\text { development processes }\end{array}$ & $\begin{array}{c}\text { Could be more disruptive } \\
\text { than \#4 and \#5, if changes } \\
\text { occur prior to steady-state } \\
\text { level }\end{array}$ \\
\hline
\end{tabular}


Figure 1: Temporal Team Selection Framework.

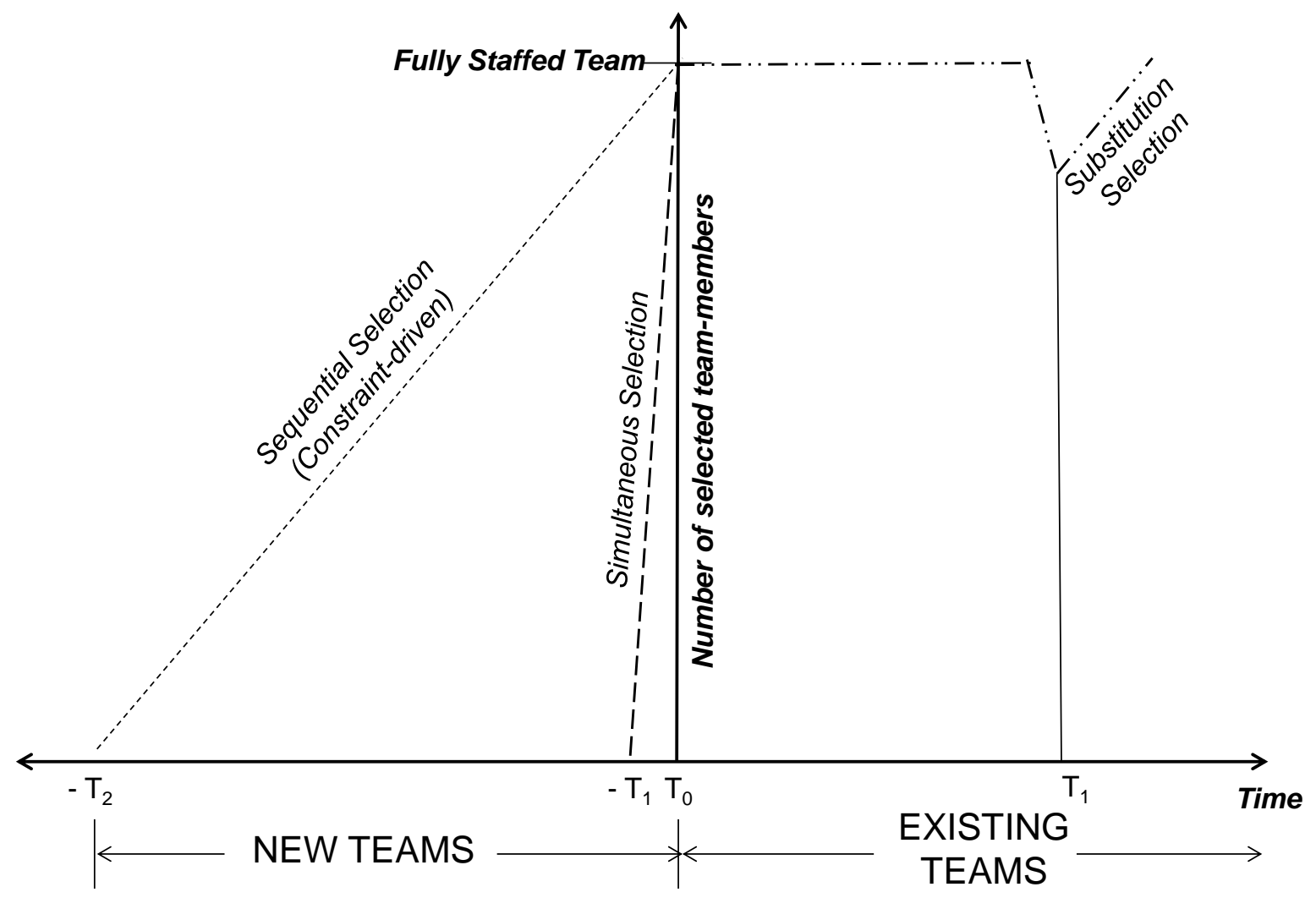


Figure 2: Two Drivers of Sequential Selection.

Panel (A)

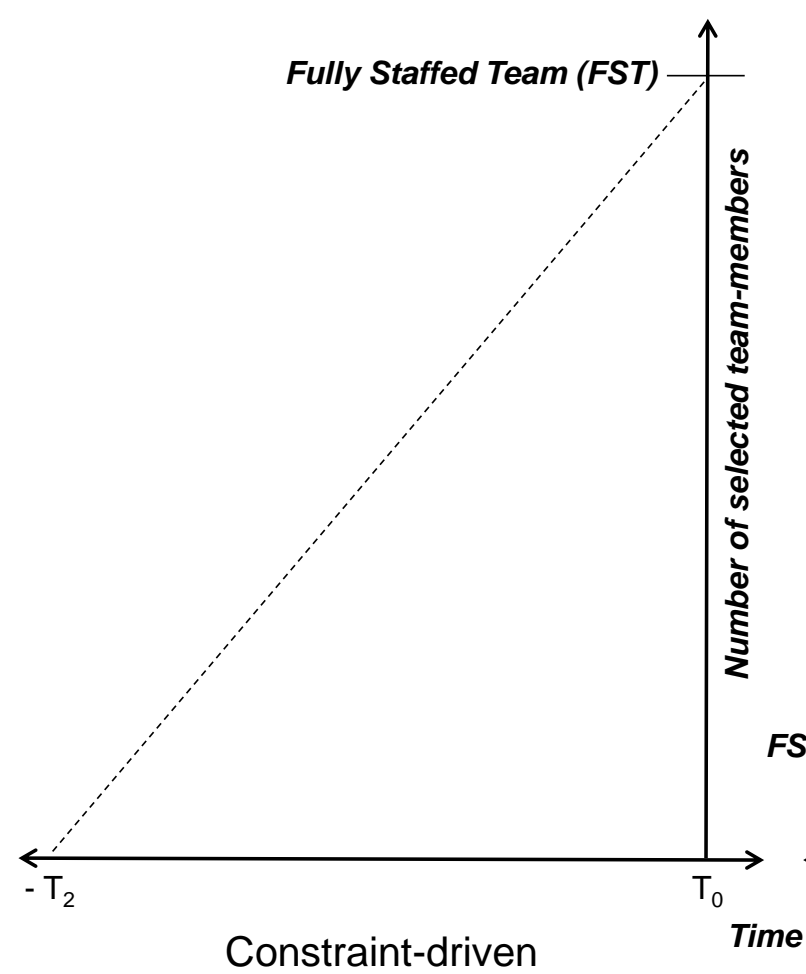

Panel (B)

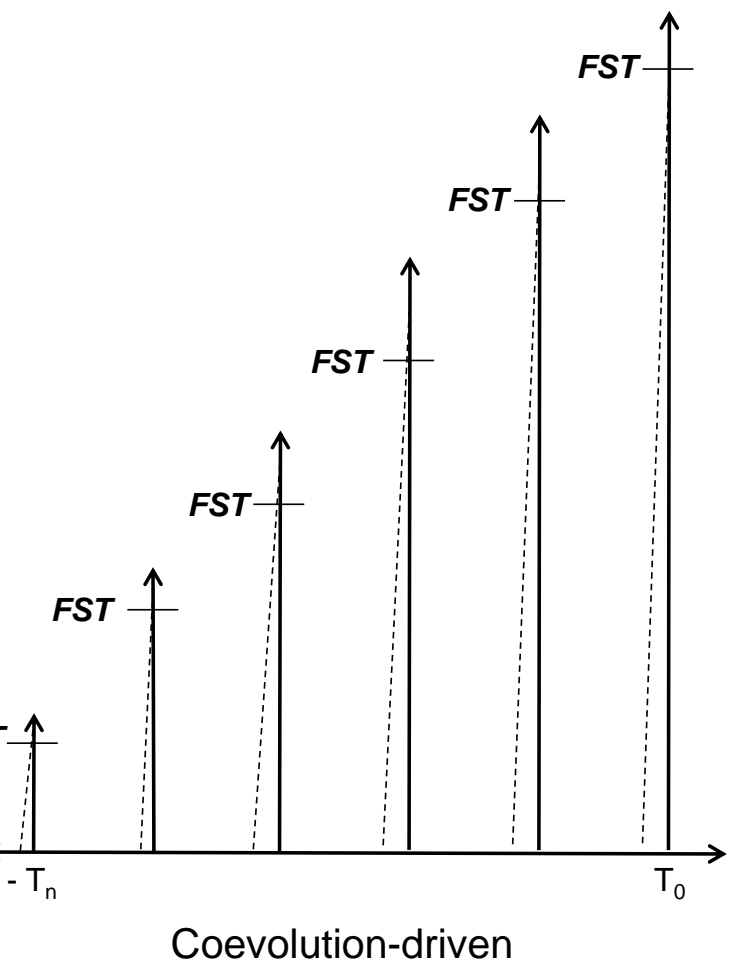

